\title{
PENGARUH AIR WUDHU TERHADAP COMPUTER EYES SYNDROME (ASTHENOPIA) PADA KARYAWAN RUMAH SAKIT ISLAM FAISAL KOTA MAKASSAR
}

\author{
Ina Mukhaiminah ${ }^{1}$, Fatmawaty Mallapiang ${ }^{2}$, Sci Hasriwiani Habo Abbas ${ }^{3}$ \\ ${ }^{1}$ Universitas Muslim Indonesia \\ ${ }^{2}$ Universitas Muslim Indonesia \\ ${ }^{3}$ Universitas Muslim Indonesia
}

Alamat korespondensi : (Inamukhaiminah@gmail.com/082343678123)

\begin{abstract}
ABSTRAK
Astenopia adalahgangguan yang dialami mata karena otot-ototnya yang dipaksa bekerja kerasterutama saat harus melihat objek dekat dalam jangka waktu lama. Semua aktifitasyang berhubungan dengan pemaksaan otot-otot tersebut untuk bekerja keras,sebagaimana otot-otot yang lain akan bisa membuat mata mengalami gangguan.Gejalanya mata terasa pegal biasanya akan muncul setelah beberapa jam kerja.Pada saat otot mata menjadi letih, mata akan menjadi tidak nyaman atau sakit.Tujuan penelitian ini adalah di ketahuinya pengaruh air wudhu terhadap computer eyes syndrome ( asthenopia ) pada karyawan Rumah Sakit Islam Faisal Kota Makassar. penelitian ini digunakan rancangan penelitianeksperimental: Quasi Experimen. yaitu rancangan eksperimen dengan cara sampel diberikan kuesioner (pengukuran sindrom astenopia) sebelum dan setelah dilakukan treatment (perlakuan) yang terdiri atas dua kelompok yakni: kelompok wudhu, dan kelompok kontrol.Sampel penelitian ini berjumlah 50 karyawan yang menggunakan komputer dan memenuhi kriteria inklusi dan di bagi kedalam dua kelompok. Analisa data menggunakan uji wilcoxon didapatkan $p=0,000<\alpha=0,05$ menunjukkan bahwa Ha diterima.untuksyndrome asthenopia sebelum intervensi terapi air wudhu menunjukkan mean rank 0,00 sedangkan untuk syndrome asthenopia sesudah intervensi terapi air wudhu menunjukkan mean rank 0,13.Kelompok kontrol dengan menggunakan uji wilcoxon didapatkan $\mathrm{p}=1,000>\alpha=0,05$ menunjukkan bahwa $\mathrm{Ha}$ diterima.untuk kelompok kontrol karena tidak ada perubahan syndrome asthenopia. Sebelum intervensi air wudhu menunjukkan mean rank 0,00 sedangkan untuk syndrome asthenopia tanpa pemberian intervensi terapi air wudhu tetap menunjukkan mean rank 0,00. Saran saya sebagai peneliti sebaiknya pihak Rumah Sakit Islam Faisal Kota Makassar lebih memperhatikan karyawan yang mengalami syndrome asthenopia untuk meningkatkan kualitas kerja karyawan.
\end{abstract}

Kata Kunci : Wudhu Dan Syndrome Asthenopia

\section{PENDAHULUAN}

Astenopia adalahgangguan yang dialami mata karena otot-ototnya yang dipaksa bekerja kerasterutama saat harus melihat objek dekat dalam jangka waktu lama. Semua aktifitasyang berhubungan dengan pemaksaan otot-otot tersebut untuk bekerja keras,sebagaimana otot-otot yang lain akan bisa membuat mata mengalami gangguan.

Data WHO menunjukkan angka kejadian asthenopia berkisar 40-90 \%. Menurut Occupational Safety and Health Administration (OSHA) di Amerika dilaporkan dari 40 juta pengguna komputer $80 \%$ mengalami kelelahan mata (Nendyah Roestijawati, 2017). World Health Organitation (WHO) mencatat angka kejadian astenopia di dunia rata-rata $75 \%$ per tahun (Sya'ban \&amp; Riski, 2014) Penelitian yang lain menemukan bahwa prevalensi astenopia 49.4\% (Hashemi, Khabazkhoob, Forouzesh, Nabovati, Yekta, \&amp; Ostadimoghaddam, 2017)
Di Rumah Sakit Islam Faisal Kota Makassar staf pada bagian rekam medis dan beberapa ruangan lainnya sering kali bekerja dengan menggunakan computer yang mana hal ini berpotensi untuk terjadinya astenopia akibat penggunaan computer terlalu lama secara terus menerus.Maka dari itu di perlukan intervensi air wudhu untuk mencegah astenopia.pada saat studi pendahuluan dengan mewawancarai 6 orang staf 5 di antaranya mengeluhkan sering sakit kepala dan matanya perih. Oleh karena itu peneliti tertarik untuk meneliti lebih lanjut mengenai “ Pengaruh Air wudhu Terhadap Computer Eyes Syndrome (Astenopia ) Pada Karyawan Di Rumah Sakit Islam Faisal Kota Makassar “

\section{BAHAN DAN METODE}

Lokasi, Populasi, Sampel

Penelitian ini dilaksanakan di Rumah Sakit Islam Faisal Kota Makassar.Waktu penelitian pada bulan September-November 
2018.

Populasi pada penelitian ini adalah karyawan pengguna komputer di Rumah Sakit Islam Faisal Kota Makassar tahun 2018 sebanyak 95 orang.

Sampel penelitian ini di pilih secara PurpossiveSampling sebesar 50 dengan menggunakan kriteria inklusi, yaitu sebagai berikut :

1. Kriteria Inklusi

a. Karyawan yang berumur antara 20 tahun hingga 55 tahun, karena daya akomodasi belum menurun.

b. Karyawan yang menggunakan komputer secara rutin setiap hari( 7 jam).

c. Tidak menderita penyakit Diabetes Melitus atau Hipertensi yang dapat menurunkan kemampuan akomodasi mata.

d. Tidak sedang sakit mata (katarak atau glukoma) yang dapat mempercepat kelelahan mata.

2. Kriteria Esklusi

a. Karyawan memakai kacamata atau contact lens saat bekerja dengan komputer.

b. Karyawan menolak berpartisipasi.

c. Karyawan tidak hadir saat penelitian dilakukan.

\section{Pengumpulan Data}

Pada kelompok inervensi sebelumdi berikan perlakuan wudhu (jam 10.00 dan 14.00) di lakukan pretest (hari 1) berupa kuesioner terkait keluhan syndrome asthenopia dan hari ke 21 di berikan postest berupa kuesioner terkait syndrome asthenopia. Hal ini di lakukan juga pada kelompok kontrol yaitu pretest hari 1 sebelum mencuci muka atau membasuh muka (jam 10.00 dan 14.00) pada hari ke 21 di berikan postest.

\section{Analisis Data}

1. Analisis Univariat

Analisis univariat dilakukan dari tiap variabel dari hasil penelitian berupa distribusi frekuensi dan presentase dari tiap variabel.

2. Analisis Bivariat

Analisis bivariat merupakan analisis untuk mengetahui intraksi dua variable atau hubungan antara variable independen dan variable dependen, dengan menggunakan data ordinal. Terlebih dahulu dilakukan uji normalitas data menggunakan uji kolmogorov-smirnov, karena data tidak terdistribusi normal maka di lanjutkan dengan uji mann whitney dengan taraf signifikan (a) $0,05 \%$ atau tingkat kepercayaan $95 \%$. Bila hasil uji statistik menunjukkan $\mathrm{p}<0,05$ maka $\mathrm{Ha}$ diterima sehingga ada hubungan yang bermakna antara variabel independen yang diteliti dengan variabel dependen. Sedangkan bila nilai $p>0,05$ maka $\mathrm{Ha}$ ditolak dan $\mathrm{Ho}$ diterima sehingga tidak ada hubungan yang bermakna antar variabel independen yang diteliti dengan variabel dependen.

\section{HASIL PENELITIAN}

1. Analisis Univariat

Tabel 1. Distribusi Keluhan Syndrome Asthenopia Berdasarkan Pretest dan Postest pada Kelompok Intervensi

\begin{tabular}{|c|c|c|c|c|}
\hline Keluhan Syndrome & \multicolumn{2}{|c|}{ Pretest } & \multicolumn{2}{c|}{ Postest } \\
\cline { 2 - 5 } Asthenopi & $\mathrm{n}$ & $\%$ & $\mathrm{n}$ & $\%$ \\
\hline Tidak mengalami & 2 & 8,0 & 24 & 96,0 \\
\hline Mengalami & 23 & 92,0 & 1 & 4,0 \\
\hline Jumlah & 25 & 100,0 & 25 & 100,0 \\
\hline
\end{tabular}

Table 1 Menunjukkan bahwa distribusi keluhan syndrome asthenopia berdasarkan pretest keluhan syndrome asthenopia untuk kelompok intervensi yang tidak mengalami adalah 2 responden $(8,0 \%)$, dan yang mengalami adalah 23 responden $(92,0)$. Sedangkan pada postest yang di beri intervensi wudhu mengalami penurunan keluhan syndrome asthenopia menjadi 1 responden (4\%).

Tabel 2. Distribusi Frekuensi Responden Berdasarkan Pretest dan Postest untuk Kelompok Kontrol di RS Islam Faisal.

\begin{tabular}{|c|c|c|c|c|}
\hline Keluhan Syndrome & \multicolumn{2}{|c|}{ Pretest } & \multicolumn{2}{c|}{ Postest } \\
\cline { 2 - 5 } Asthenopia & $\mathrm{n}$ & $\%$ & $\mathrm{n}$ & $\%$ \\
\hline Tidak mengalami & 23 & 92,0 & 23 & 92,0 \\
\hline Mengalami & 2 & 8,0 & 2 & 8,0 \\
\hline Jumlah & 25 & 100,0 & 25 & 100,0 \\
\hline
\end{tabular}

Tabel 2 menunjukkan bahwa distribusi Keluhan syndrome asthenopia berdasarkan pretest untuk kelompok kontrol yang tidak mengalami adalah 23 responden $(92,0 \%)$, dan yang mengalami adalah 2 responden $(8,0 \%)$. menunjukkan bahwa distribusi keluhan syndrome asthenopia berdasarkan postest untuk kelompok kontrol yang tidak mengalami adalah 23 responden $(92,0 \%)$, dan yang mengalami adalah 2 responden $(8,0 \%)$.

2. Analisis Bivariat

Tabel 3. Hasil Analisis Uji Statistik Wilcoxon Signed Rank TestSebelum dan Sesudah Berwudhu pada Kelompok Intervensi 


\begin{tabular}{|l|c|c|c|}
\hline & $\mathrm{n}$ & Mean Rank & $p$ \\
\hline Pretest & 25 & 0.00 & \multirow{2}{*}{0,000} \\
\hline Postest & 25 & 0,13 & \\
\hline
\end{tabular}

Berdasarkan tabel 3 menunjukkan bahwa dengan menggunakan uji wilcoxon didapatkan $p=0,000<\alpha=0,05$ yang berarti bahwa Ha diterima. Pada pre test menunjukkan bahwa sebelum di berikan intervensi wudhu mean rank 0,00 sedangkan untuk syndrome asthenopia sesudah intervensi air wudhu mean rank 0,13 ini menunjukkan bahwa terjadi perubahan syndrome asthenopia sesudah intervensiair wudhu. Dari data tersebut dapat disimpulkan bahwa ada pengaruh yang signifikan antara intervensi wudhu terhadap syndrome asthenopia pada kelompok intervensi di RS.islam faisal Makassar.

Tabel 4. Hasil Analisis Uji Statistik Wilcoxon Signed Rank Test Syndrome Asthenopia Sebelum dan Sesudah Berwudhu pada Kelompok Kontrol RS Islam Faisal Makassar Tahun 2018.

\begin{tabular}{|c|c|c|c|}
\hline & $\mathrm{n}$ & Mean Rank & $p$ \\
\hline Pretest & 25 & 0.00 & 1,000 \\
\hline Postest & 25 & 0,00 & \\
\hline
\end{tabular}

Berdasarkan tabel 4 menunjukkan bahwa dengan menggunakan uji wilcoxon didapatkan $\mathrm{p}=1,000>\alpha=0,05$ yang berarti bahwa Ha diterima. untuk kelompok kontrol karena tidak ada perubahan syndrome asthenopia. Sebelum intervensi air wudhu menunjukkan mean rank 0,00 sedangkan untuk syndrome asthenopia hanya pemberian membasuh muka tetap menunjukkan mean rank 0,00 ini menunjukkan bahwa tidak terjadi perubahan syndrome asthenopia. Dari data tersebut dapat disimpulkan bahwa tidak ada pengaruh yang signifikan pada kelompok kontrol karena kelompok kontrol tidak diberikan intervensi wudhu hanya membasuh muka sehingga tidak ada perubahan kelelahan mata.

\section{PEMBAHASAN}

1. Pengaruh Air Wudhu Terhadap Syndrome Asthenopia pada kelompok intervensi.

Pengambilan air wudhu di lakukan $2 x$ sehari dengan cara mengambil air wudhu pada hari 1 dan pada hari 21 kemudian menjelaskan kepada responden manfaat air wudhu bagi kesehatan. Pada hari pertama ustadz menjelaskan cara mengambil air wudhu dengan benar menurut syariat islam, di hari berikutnya responden mempraktekkan langsung cara mengambil air wudhu dengan benar.yang selanjutnya dilakukan analisis dengan menggunakan Uji Wilcoxon Signed Ranks Test

Berdasarkan hasil penelitian yang di lakukan terhadap 25 responden pada kelompok intervensi menunjukkan bahwa pada variabel air wudhu saat (pretest) di peroleh nilai mean 0,00 , sedangkan pada saat (postest) di peroleh nilai mean 0,13 .

Hasil uji statistic di dapatkan $p=0,000$ dapat di simpulkan bahwa terjadi perubahan signifikan pada variabel sebelum dan sesudah wudhu.

Hal ini disebabkan oleh intervensi yang diberikan yaitu air wudhu. Air wudhu mempunyai banyak manfaat untuk kesehatan manusia.Salah satunya yaitu untuk kesehatan mata, karena pada saat berwudhu dianjurkan untuk tidak menutup mata apabilamembasuh wajah. Air yang masuk ke mata pada saat berwudhu akan membuat mata anda rileks dan segar, sehingga mata anda akan kembali cerah setelah lelah bekerja.

Pada saat membasuh wajah, dianjurkan untuk tidakmenutup mata sehingga air wudhu bisa terkena mata yang akan berpengaruh positif terhadap kelelahan mata. Membasuh anggota tubuh disertai dengan pemijatan pada titik-titik tertentu akan melancarkan aliran darah kita dan dapat merefleksi organ-organ yang bersangkutan. Dengan lancarnya aliran darah terebut, maka dapat mencegah dan menyembuhkan berbagai macam penyakit yang berhubungan dengan organ-organ tertentu seperti tangan, mulut, hidung, muka, kepala dan kaki.

Dalam Islam, hidroterapi ini dilakukan paling tidak lima kali sehari, yakni ketika berwudhu sebelum melaksanakan shalat lima waktu. Hidroterapi dengan berwudhu ini memiliki kelebihan daripada hidroterapi yang biasa dilakukan oleh seseorang. Hal ini dikarenakan hidroterapi dengan berwudhu disertai kata-kata positif (niat dan do'a), yang menurut Emoto (2011), kata-kata positif ini dapat bermanfaat bagi manusia.

Chaitow (2011), seorang osteopath dan naturalpath, mengungkapkan bahwa, Penggunaan air dingin dalam waktu singkat (kurang dari 1 menit) akan mengakibatkan kontraksi-kontraksi pembuluh darah lokal. Ini memiliki efek terjadinya dekongesi pada jaringanjaringan tubuh dan dengan cepat diikuti oleh sebuah reaksi dimana pembuluh- 
pembuluh darah terbuka dan jaringanjaringan dibersihkan dengan darah yang banyak mengandung oksigen segar.

Hal ini Senada dengan itu, Muhyidin (2011) mengatakan bahwa, "Air yang mengandung elektrolit-elektrolit akan membuat pembuluh-pembuluh darah mengalami vasoditalasi (pelebaran)." Seperti halnya dengan wudhu, ketika air wudhu membasuh anggota wudhu, pembuluh-pembuluh darah akan terbuka dan mengalami vasoditalasi (pelebaran).

2. Pengaruh Air Wudhu Terhadap Syndrome Asthenopia pada kelompok control.

Pada kelompok kontrol ini di berikan perlakuan cuci muka atau membasuh muka di lakukan 2x sehari pada pukul 10.00 dan 14.00 selama 21 hari kemudian responden mempraktekkan langsung cara mencuci muka atau membasuh muka yang selanjutnya dilakukan analisis dengan menggunakan Uji Wilcoxon Signed Ranks Test

Berdasarkan hasil penelitian yang di lakukan terhadap 25 responden pada kelompok kontrol menunjukkan bahwa pada saat mencuci muka atau membasuh muka saat (pretest) di peroleh nilai mean 0,00 , sedangkan pada saat (postest) di peroleh nilai mean 0,00 .

Hasil uji statistic di dapatkan $p=$ 0,000 dapat di simpulkan bahwa tidak ada perubahan signifikan pada variabel sebelum dan sesudah mencuci muka atau membasuh muka.

Berdasarkan hasil penelitian yang dilakukan peneliti pada kelompok kontrol tidak ada perubahan signifikan pada saat dilakukan pretest dan postest. Kelompok kontrol masih mengalami kelelahan mata pada saat bekerja karena tidak diberikan intervensi air wudhu untuk mengurangi syndrome asthenopia.

\section{KESIMPULAN}

1. Ada Pengaruh Karakteristik Responden terhadap Computer Eyes Syndrome (Asthenopia) pada Karyawan Rumah Sakit Islam Faisal Makassar.

2. Ada Pengaruh Air Wudhu terhadap Computer Eyes Syndrome (Asthenopia) pada Karyawan Rumah Sakit Islam Faisal Makassar.

\section{SARAN}

1. Diharapkan pihak Rumah Sakit Islam Faisal Makassar dapat membudayakan berwudhu sebelum dan sesudah menggunakan komputer untuk karyawan yang mengalami Syndrome Asthenopia

2. memberikan fasilitas komputer yang layak untuk di pakai atau sudah memakai anti radiasi dan ruangan yang di tempeli wallpaper agar mata tidak mudah mengalammi Syndrome Asthenopia.

\section{DAFTAR PUSTAKA}

Akrom, M. (2010). Terapi Wudhu Sempurna Sholat, Bersihkan Penyakit. Yogyakarta: Mutiara Media.

Azkadina, A. (2012). Hubungan antara faktor risiko individual dan komputer terhadap kejadian Computer Vision Syndrome. Semarang: Fakultas Kedokteran Universitas Diponegoro.

Budijanto, D. (2016). Populasi, Sampling, dan Besar Sampel. Jakarta: PUSDATIN- Kementerian Kesehatan RI.

Hadi. (2016). Manfaat Wudhu untuk Kesehatan Mata. Dipetik September 03, 2018, dari http://nabiungkangkung.com: http://nabiungkangkung.com/2014/01/manfaat-wudhu-untuk-kesehatanmata.html

Hashemi, H., Khabazkhoob, M., Forouzesh, S., Nabovati, P., Yekta, A. A., \& Ostadimoghaddam, H. (2017). The Prevalence of Asthenopia and its Determinants Among Schoolchildren. J Compr Ped. , 8(1):e43208.

Lukmawati, L. (2015). Ketenangan: Makna Dawamul Wudhu. Palembang: Fakultas Ushuluddin Dan Pemikiran Islam Universitas Islam Negeri Raden Fatah.

Radhit. (2012). Gunakan Aturan 20-20-20 Jika Berlama-lama di Depan Komputer. Dipetik September 02, 2018, dari www.apakabardunia.com: http://www.apakabardunia.com/2012/07/gunakan-aturan-20-20-20-jikaberlama.html

Rosenfield, M. (2011). Computer vision syndrome: a review of ocular causes and potential treatments. $J$ Ophthalmic Physiol Opt , 50(3) : 253-262.

Rusyd, I. (2015). Bidayatul Mujtahid Wa Nihayatul Muqtashid. Surabaya: Al-Hidayah. 
Sya'ban, A. R., \& Riski, I. M. (2014). Faktor-faktor yang berhubungan dengan kejadian keluhan kelelahan mata pada karyawan pengguna komputer PT Grapari Telkomsel kota Kendari. Proseding Seminar Bisnis \& Teknologi ISSN : 2407-6171 (hal. 754-768). Jakarta: IBI Darmajaya.

Tribley, J., McClain, S., Karbasi, A., \& Kaldenberg, J. (2011). Tips for computer vision syndrome relief and prevention. Work, 39(1): 85-87.

Zulaiha, S., Rachman, I., \& Marisdayana, R. (2018). Pencahayaan, Jarak Monitor, dan Paparan Monitor sebagai Faktor Keluhan Subjektif Computer Vision Syndrome (CVS). Kes Mas: Jurnal Fakultas Kesehatan Masyarakat, Volume 12, Issue 1, March, pp. $38 \sim 44$. 